\title{
Lactic acid bacterial inoculant effects on the vitamin content of alfalfa and Chinese leymus silage
}

\author{
Tingting Jia', Zhiqiang Sun ${ }^{1}$, Run Gao ${ }^{1}$, and Zhu Yü ${ }^{1, *}$
}

* Corresponding Author: Zhu Yu Tel: +81-010-62733414, Fax: +81-010-62733414, E-mail: yuzhu33150@sina.com

'Department of grassland production and utilization, College of Grassland Science and Technology, China Agricultural University, Beijing 100193, China

ORCID

Tingting Jia

https://orcid.org/0000-0001-5554-170X

Zhiqiang Sun

https://orcid.org/0000-0002-3231-8107

Run Gao

https://orcid.org/0000-0003-1998-6319

Zhu Yu

https://orcid.org/0000-0003-3271-1272

Submitted Feb 15, 2019; Revised Apr 1, 2019; Accepted Apr 20, 2019
Objective: Information regarding the vitamin content of silage is limited. This study investigated the changes in the vitamin content of alfalfa and Chinese leymus silages with or without a lactic acid bacterial inoculant.

Methods: Alfalfa at the early flowering stage and Chinese leymus at the full-bloom stage were harvested. The treatments for each forage type were control (deionized water only) and $1 \times 10^{6}$ colony-forming units Lactobacillus plantarum (LP)/g fresh matter. After 45 days of ensiling, all silages were sampled for evaluating the vitamin content, fermentation quality and chemical composition.

Results: The LP inoculant decreased the $\mathrm{pH}$ value and ammonia nitrogen content of the alfalfa and Chinese leymus silages and significantly $(\mathrm{p}<0.05)$ increased the lactic acid, acetic acid concentrations and Flieg's points. Prior to ensiling, the levels of five B-group vitamins (thiamin, riboflavin, niacin, pantothenic acid, and pyridoxine) and $\alpha$-tocopherol in alfalfa were significantly $(\mathrm{p}<0.01)$ higher than those in Chinese leymus. Ensiling decreased the levels of the five B-group vitamins in both alfalfa and Chinese leymus while increasing the a-tocopherol content of Chinese leymus. The thiamin, riboflavin, niacin and pantothenic acid levels in the LP-treated silage were significantly $(\mathrm{p}<0.05)$ lower than those in the untreated silage for the alfalfa and Chinese leymus. The $\alpha$-tocopherol content in the LP-treated alfalfa silage was significantly $(\mathrm{p}<0.05)$ higher than that in the untreated alfalfa silage. There was no significant $(\mathrm{p}>0.05)$ difference in pyridoxine content between the untreated and LP-treated silages for both forages.

Conclusion: With or without LP inoculation, the levels of the five B-group vitamins (thiamin, riboflavin, niacin, pantothenic acid, and pyridoxine) in alfalfa and Chinese leymus decreased after 45 days of ensiling, while the $a$-tocopherol content of Chinese leymus increased. The LP inoculant improved the fermentation quality of both the alfalfa and Chinese leymus silages but increased the thiamin, riboflavin, niacin, and pantothenic acid loss in the two forages after fermentation.

Keywords: Alfalfa Silage; Chinese Leymus Silage; Lactobacillus Inoculants; Vitamin

\section{INTRODUCTION}

Vitamins are organic nutrients that are essential in minute quantities for the nutrition of ruminants [1]. Vitamins act as coenzymes and precursors of coenzymes in the regulation of metabolic processes [2]. Fresh or conserved forages are important dietary sources of natural vitamins in ruminants $[1,3]$. The concentrate used in ruminant diets does not contain any natural vitamins or vitamin precursors [4]. $\alpha$-Tocopherol and $\beta$-carotene in forage have received much attention due to their antioxidant properties [3,5-9]. The level of $\alpha$-tocopherol in ensiled forage was seen to be higher than that in hay [6,7]. There is little information regarding the levels of B-group vitamins in silage and the effects of additives on the B vitamin content. B-group vitamins are essential for ruminants, and vitamin B deficiency can lead 
to different degrees of metabolic disorders [7]. It has been shown that there is an increasing need for B vitamins in ruminants due to the increased demand for high productivity and quality of animal products [4]. However, to the best of our knowledge, there have been few studies on B-group vitamins in silage. Additional information is required regarding the changes in B vitamin levels in silage.

Alfalfa and Chinese leymus are the main forage sources for animal diets in China. Storage of this forage as silage is a good way to retain the nutritional content. Additives are added during forage ensilage to achieve high-quality silage. The additives strongly influence the fermentation process of silage and may influence the vitamin content in silage [7]. Shingfield et al [8] demonstrated an increase in the $\alpha$-tocopherol content in silage via the use of an inoculant enzyme preparation. Liu et al [9] reported that the use of additives decreased the $\alpha$-tocopherol and $\beta$-carotene levels in silages. However, there are no reports in the literature on the effect of lactic acid bacterial additives on B-group vitamins in silage. Certel et al [10] and Ochanda et al [11] found that fermentation influences the concentrations of B-group vitamins in food. However, information regarding B-group vitamins in silage is limited. Therefore, this study was undertaken to provide information on the effects of lactic acid bacterial inoculants on the vitamin content of alfalfa and Chinese leymus silage. Additionally, the fermentation quality and chemical composition of alfalfa and Chinese leymus silage were also evaluated.

\section{MATERIALS AND METHODS}

\section{Silage materials and ensiling}

Alfalfa and Chinese leymus were grown in Guyuan County $\left(41^{\circ} 42^{\prime}-41^{\circ} 57^{\prime} \mathrm{N}, 115^{\circ} 32^{\prime}-115^{\circ} 59^{\prime} \mathrm{E}\right)$, Hebei Province, P. R. China. Alfalfa at the early flowering stage and Chinese leymus at the full-bloom stage were harvested with 4 to $5-\mathrm{cm}$ stubble height and wilted for 2 hours. Then, the alfalfa and Chinese leymus forages were chopped into 1 to 2 -cm pieces with a forage cutter. The treatments for each forage type were control (deionized water only) and Lactobacillus plantarum inoculant (LP). The lactic acid bacterial strain LP was isolated from the grass and identified as L. plantarum via $16 \mathrm{~S}$ rDNA sequencing. The LP strain was inoculated at $1 \times 10^{6}$ colony-forming units/g fresh matter. Approximately $300 \mathrm{~g}$ of chopped alfalfa and Chinese leymus forages were filled into polyethylene bag silos $\left(30 \times 40 \mathrm{~cm} ; 0.19 \mathrm{~mm}\right.$ thickness; $50 \mathrm{~cm}^{3} \mathrm{~m}^{-2}$ day $\left.^{-1} 0.1 \mathrm{Mpa}^{-1}\right)$. Each treatment had three repetitions. The silos were sealed with a vacuum sealer (FW3150; Fresh World Electric Co., Ltd., Guangzhou, China). All the silos were preserved at ambient temperature in a dark room, then opened and sampled after ensiling for 45 days.

\section{Chemical analysis}

Twenty-gram samples of alfalfa and Chinese leymus silages were mixed with $180 \mathrm{~mL}$ of distilled water and then homogenized in a juicer for $2 \mathrm{~min}$. The mixture was filtered, and then, the filtrate was used for determination of $\mathrm{pH}$ and organic acid and ammonia nitrogen concentrations. The $\mathrm{pH}$ was measured by using a $\mathrm{pH}$ meter (PHS-3C, INESA Scientific Instrument Co., Ltd., Shanghai, China). The organic acid (lactic, acetic, propionic and butyric acids) levels were determined by high performance liquid chromatography (HPLC; column: Shodex RS Pak KC-811, Showa Denko KK, Kawasaki, Japan; detector: DAD, 210 nm, SPD-20A, Shimadzu Co., Ltd., Kyoto, Japan; eluent: $3 \mathrm{mmol} / \mathrm{L} \mathrm{HClO}_{4}$, at a flow rate of $1.0 \mathrm{~mL} / \mathrm{min}$; column temperature: $50^{\circ} \mathrm{C}$ ). The ammonia nitrogen concentration was analyzed by the phenol and sodium hypochlorite method [12]. The buffering capacity of the alfalfa and Chinese leymus materials was determined by the method described by Playne and McDonald [13]. The dry matter (DM) content was measured after oven-drying at $65^{\circ} \mathrm{C}$ for 48 hours. The oven-dried samples were first milled and passed through a $1.0-\mathrm{mm}$ screen and then used for analysis of the water-soluble carbohydrate (WSC), crude protein (CP), neutral detergent fiber (NDF), acid detergent fiber (ADF), and hemicellulose (HC) levels. The WSC content was measured by the anthrone method [14]. The CP content was analyzed by using method 976.05 of the Association of Official Analytical Chemists [15]. The $\mathrm{NDF}$ and ADF levels were measured by the method described by Van Soest et al [16]. The HC content of the samples was estimated as the NDF value minus the ADF value.

\section{Vitamin analysis}

The vitamin concentrations were determined by HPLC. The sample (100 g) was freeze dried using a vacuum freeze-drying machine for 2 days (FreeZone 4.5L, LABCONCO Corp., Kansas City, MO, USA) before analysis. The freeze-dried samples were then ground and passed through a 1.0-mm screen.

Thiamin concentrations were determined in duplicate based on the method of GB/T 14700-2018. The extraction solution was prepared as follows: $107 \mathrm{~g}$ of $\mathrm{NH}_{4} \mathrm{Cl}$ was dissolved in 1,000 $\mathrm{mL}$ of ultrapure water; then, the $\mathrm{pH}$ was adjusted to 3 to 4 with $2 \mathrm{~mol} / \mathrm{L} \mathrm{HCl} ; 900 \mathrm{~mL}$ of this $\mathrm{NH}_{4} \mathrm{Cl}$ solution was mixed with $100 \mathrm{~mL}$ of carbinol (Sigma-Aldrich, Darmstadt, Germany). Then, $5 \mathrm{~g}$ of sample and $70 \mathrm{~mL}$ of extraction solution were mixed in a $100-\mathrm{mL}$ brown-glass volumetric flask. Next, the samples were incubated in an ultrasonic bath (30 min). After cooling in an ice bath, the volume was made up to $100 \mathrm{~mL}$, and the mixture was centrifuged $(8,000 \mathrm{r} / \mathrm{min}, 5 \mathrm{~min})$. The supernatant was collected and passed through a $0.45-\mu \mathrm{m}$ syringe filter. Twenty microliters of the filtered supernatant were injected into an HPLC instrument. The samples were examined on a Pursuit $5-\mu \mathrm{m}$ C18 column $(150 \times 4.6 \mathrm{~mm}$; Agilent, Ammerbuch, Germany). The mobile phase used was prepared as follows: $1.1 \mathrm{~g}$ of sodium heptanesulfonate 
and $50 \mathrm{mg}$ of disodium ethylenediamine tetraacetic acid were dissolved in $700 \mathrm{~mL}$ of ultrapure water, and after total dissolution, $25 \mathrm{~mL}$ of glacial acetic acid and $10 \mathrm{~mL}$ of triethylamine (Sigma-Aldrich, Germany) were added. Then, the solution was made up to $1,000 \mathrm{~mL}$, and the $\mathrm{pH}$ value was adjusted to 3.7. Then, $800 \mathrm{~mL}$ of this solution was mixed with $200 \mathrm{~mL}$ of carbinol (Sigma-Aldrich, Germany). The flow rate was $1.0 \mathrm{~mL} / \mathrm{min}$, and the diode array detector was operated at a wavelength of $242 \mathrm{~nm}$. The column temperature was $25^{\circ} \mathrm{C}$ to $28^{\circ} \mathrm{C}$.

Riboflavin levels were analyzed in duplicate according to the method of GB/T 14701-2002. The extraction solution was prepared as follows: $50 \mathrm{mg}$ of disodium ethylenediamine tetraacetic acid was dissolved in $700 \mathrm{~mL}$ of ultrapure water, and after total dissolution, $25 \mathrm{~mL}$ of glacial acetic acid and $5 \mathrm{~mL}$ of triethylamine were added, and the volume was adjusted to $1,000 \mathrm{~mL}$. Then, $5 \mathrm{~g}$ of sample and $30 \mathrm{~mL}$ of extraction solution were mixed in a $100-\mathrm{mL}$ brown-glass volumetric flask. Next, the samples were incubated in an $80^{\circ} \mathrm{C}$ to $100^{\circ} \mathrm{C}$ water bath $(30 \mathrm{~min})$. After cooling in an ice bath, $14 \mathrm{~mL}$ of carbinol was added. Then, the volume was made up to 100 $\mathrm{mL}$ with extraction solution, and the solution was centrifuged $(8,000 \mathrm{r} / \mathrm{min}, 5 \mathrm{~min})$. The supernatant was collected and passed through a $0.45-\mu \mathrm{m}$ syringe filter. Then, $10 \mu \mathrm{L}$ of the filtered supernatant was injected into an HPLC instrument. The samples were examined on a Pursuit 5- $\mu \mathrm{m} \mathrm{C18}$ column ( $150 \times 4.6 \mathrm{~mm}$; Agilent, Germany). The mobile phase was prepared as follows: $1.1 \mathrm{~g}$ of sodium heptanesulfonate and $50 \mathrm{mg}$ of disodium ethylenediamine tetraacetic acid was dissolved in $700 \mathrm{~mL}$ of ultrapure water, and after total dissolution, $25 \mathrm{~mL}$ of glacial acetic acid and $5 \mathrm{~mL}$ of triethylamine (Sigma-Aldrich, Germany) were added. The solution was then made up to $1,000 \mathrm{~mL}$, and the $\mathrm{pH}$ value was adjusted to 3.4; $860 \mathrm{~mL}$ of this solution were mixed with 140 $\mathrm{mL}$ of carbinol (Sigma-Aldrich, Germany). The flow rate was $0.8 \mathrm{~mL} / \mathrm{min}$, and the diode array detector was operated at a wavelength of $280 \mathrm{~nm}$. The column temperature was $25^{\circ} \mathrm{C}$ to $28^{\circ} \mathrm{C}$.

Niacin levels were examined according to the method of GB/T 17813-2018. The extraction solution was prepared as follows: $50 \mathrm{mg}$ of disodium ethylenediamine tetraacetic acid was dissolved in $800 \mathrm{~mL}$ of ultrapure water, and then, $20 \mathrm{~mL}$ of glacial acetic acid and $5 \mathrm{~mL}$ of triethylamine were added; after thorough mixing, this solution was mixed with $200 \mathrm{~mL}$ of carbinol (Sigma-Aldrich, Germany). Then, $5 \mathrm{~g}$ of sample, $1 \mathrm{~g}$ of disodium ethylenediamine tetraacetic acid and $70 \mathrm{~mL}$ of extraction solution were mixed in a $100-\mathrm{mL}$ brown-glass volumetric flask. Next, the samples were incubated in an ultrasonic bath (15 $\mathrm{min})$. After cooling in an ice bath, the volume was made up to $100 \mathrm{~mL}$ with extraction solution, and the mixture was centrifuged $(8,000 \mathrm{r} / \mathrm{min}, 5 \mathrm{~min})$. The supernatant was collected and passed through a $0.45-\mu \mathrm{m}$ syringe filter.
Then, $20 \mu \mathrm{L}$ of the filtered supernatant was injected into an HPLC instrument. The samples were examined on a Pursuit 5- $\mu \mathrm{m}$ C18 column ( $150 \times 4.6 \mathrm{~mm}$; Agilent, Germany). The mobile phase was prepared as follows: $1.1 \mathrm{~g}$ of sodium heptanesulfonate and $50 \mathrm{mg}$ of disodium ethylenediamine tetraacetic acid were dissolved in $1,000 \mathrm{~mL}$ of ultrapure water, and after total dissolution, $20 \mathrm{~mL}$ of glacial acetic acid and $5 \mathrm{~mL}$ of triethylamine (Sigma-Aldrich, Germany) were added, and the $\mathrm{pH}$ value was adjusted to 4.0 . Then, $800 \mathrm{~mL}$ of this solution was mixed with $200 \mathrm{~mL}$ of carbinol (Sigma-Aldrich, Germany). The flow rate was $1.0 \mathrm{~mL} / \mathrm{min}$, and the diode array detector was operated at a wavelength of $262 \mathrm{~nm}$.

Pantothenic acid levels were measured based on the method of GB/T 18397-2014. Five grams of sample and $50 \mathrm{~mL}$ of the mobile phase were mixed in a $150-\mathrm{mL}$ conical flask. The samples were incubated in an ultrasonic bath (15 min). After cooling in an ice bath, the samples were centrifuged $(8,000$ $\mathrm{r} / \mathrm{min}, 5 \mathrm{~min}$ ). The supernatant was collected and passed through a $0.45-\mu \mathrm{m}$ syringe filter. Then, $10 \mu \mathrm{L}$ of the filtered supernatant was injected into an HPLC instrument. The samples were examined on a Pursuit $5-\mu \mathrm{m}$ C18 column $(150 \times 4.6$ $\mathrm{mm}$; Agilent, Germany). The mobile phase was prepared by adding $50 \mathrm{~mL}$ of acetonitrile to $950 \mathrm{~mL}$ of $0.05 \%$ phosphoric acid (aqueous solution). The flow rate was $1.0 \mathrm{~mL} / \mathrm{min}$, and the diode array detector was operated at a wavelength of 200 nm.

Pyridoxine levels were determined based on the method of GB/T 14702-2002. The extraction solution was prepared as follows: $50 \mathrm{mg}$ of disodium ethylenediamine tetraacetic acid was dissolved in $700 \mathrm{~mL}$ of ultrapure water, and then, $25 \mathrm{~mL}$ of glacial acetic acid and $5 \mathrm{~mL}$ of triethylamine were added, and the volume was adjusted to $1,000 \mathrm{~mL}$. Then, $800 \mathrm{~mL}$ of this solution was mixed with $200 \mathrm{~mL}$ of carbinol (SigmaAldrich, Germany). Then, $5 \mathrm{~g}$ of sample and $70 \mathrm{~mL}$ of sodium dihydrogen phosphate solution were mixed in a $100-\mathrm{mL}$ brown-glass volumetric flask. Next, the samples were incubated in an ultrasonic bath (20 min). After cooling in an ice bath, the volume was made up to $100 \mathrm{~mL}$ with extraction solution, and the mixture was centrifuged $(8,000 \mathrm{r} / \mathrm{min}, 5$ $\mathrm{min})$. The supernatant was collected and passed through a $0.45-\mu \mathrm{m}$ syringe filter. Then, $20 \mu \mathrm{L}$ of filtered supernatant was injected into an HPLC instrument. The samples were examined on a Pursuit $5-\mu \mathrm{m}$ C18 column $(250 \times 4.6 \mathrm{~mm}$; Agilent, Germany). The mobile phase was prepared as follows: $1.1 \mathrm{~g}$ of sodium heptanesulfonate and $50 \mathrm{mg}$ of disodium ethylenediamine tetraacetic acid were dissolved in $700 \mathrm{~mL}$ of ultrapure water, and after total dissolution, $25 \mathrm{~mL}$ of glacial acetic acid and $5 \mathrm{~mL}$ of triethylamine (Sigma-Aldrich, Germany) were added, and the volume was adjusted to $1,000 \mathrm{~mL}$ with ultrapure water. The $\mathrm{pH}$ was adjusted to 4.0. Then, 800 $\mathrm{mL}$ of this solution was mixed with $200 \mathrm{~mL}$ of carbinol (Sigma-Aldrich, Germany). The flow rate was $1.0 \mathrm{~mL} / \mathrm{min}$, and 
the diode array detector was operated at a wavelength of 290 nm.

The a-tocopherol levels were analyzed based on the method of GB/T 17812-2008. The extraction solution was prepared as follows: $50 \mathrm{mg}$ of disodium ethylenediamine tetraacetic acid was dissolved in $700 \mathrm{~mL}$ of ultrapure water, and then, $25 \mathrm{~mL}$ of glacial acetic acid and $5 \mathrm{~mL}$ of triethylamine were added, and the volume was adjusted to $1,000 \mathrm{~mL}$. Then, 800 $\mathrm{mL}$ of this solution was mixed with $200 \mathrm{~mL}$ of carbinol (Sigma-Aldrich, Germany). Then, $5 \mathrm{~g}$ of sample and $80 \mathrm{~mL}$ of carbinol were mixed in a $100-\mathrm{mL}$ brown-glass volumetric flask. Next, the samples were incubated in an ultrasonic bath $\left(60^{\circ} \mathrm{C}, 20 \mathrm{~min}\right)$. After cooling in an ice bath, the volume was made up to $100 \mathrm{~mL}$ with carbinol, and the solution was centrifuged ( $8,000 \mathrm{r} / \mathrm{min}, 5 \mathrm{~min})$. The supernatant was collected and passed through a $0.45-\mu \mathrm{m}$ syringe filter. Then, $20 \mu \mathrm{L}$ of the filtered supernatant was injected into and HPLC instrument. The samples were examined on a Pursuit 5- $\mu \mathrm{m} \mathrm{C18}$ column $(250 \times 4.6 \mathrm{~mm}$; Agilent, Germany). The mobile phase was composed of $98 \mathrm{~mL}$ of carbinol and $2 \mathrm{~mL}$ of ultrapure water. The flow rate was $1.0 \mathrm{~mL} / \mathrm{min}$, and the diode array detector was operated at a wavelength of $285 \mathrm{~nm}$.

\section{Calculation of the Flieg's point}

The quality of the alfalfa and Chinese leymus silage was estimated based on the Flieg's point index, which was calculated by using the following equation [17]:

Flieg’s point $=220+[(2 \times \% \mathrm{DM})-15]-40 \times \mathrm{pH}$

\section{Statistical analysis}

The vitamin content, fermentation quality, and chemical com- position data were analyzed by analysis of variance (ANOVA) using the general linear model-univariate procedure of SPSS 19.0 software [18]. ANOVAs were performed for forage types and treatments (control vs LP inoculant) as the two main parameters and for the interaction between the two parameters. The mean values were compared using Duncan's multiplerange tests. Differences between means were considered significant when $\mathrm{p}<0.05$.

\section{RESULTS}

\section{Chemical composition and vitamin content of alfalfa and Chinese leymus forages before ensiling}

The chemical composition and vitamin content of the alfalfa and Chinese leymus forages before ensiling are summarized in Table 1. The DM levels in the alfalfa and Chinese leymus were 358.2 and $450.1 \mathrm{~g} / \mathrm{kg}$, respectively. The buffering capacity of alfalfa was significantly $(\mathrm{p}<0.001)$ higher than that of Chinese leymus. The NDF, ADF, HC, and WSC levels in alfalfa were significantly $(p<0.01)$ lower than those in Chinese leymus. The CP level in alfalfa was significantly $(\mathrm{p}<0.001)$ higher than that in Chinese leymus. The thiamin, riboflavin, niacin, pantothenic acid, pyridoxine and $\alpha$-tocopherol concentrations in alfalfa were significantly $(\mathrm{p}<0.01)$ higher than those in Chinese leymus.

\section{Fermentation characteristics of alfalfa and Chinese leymus silages}

The fermentation characteristics of the alfalfa and Chinese leymus silages are presented in Table 2. The LP inoculant significantly $(\mathrm{p}<0.05)$ decreased the $\mathrm{pH}$ values and significantly $(\mathrm{p}<0.05)$ increased the lactic acid and acetic acid levels of the

Table 1. Chemical composition and vitamin content of alfalfa and Chinese leymus prior to treatment and ensiling

\begin{tabular}{|c|c|c|c|c|}
\hline \multirow{2}{*}{ Items } & \multicolumn{2}{|c|}{ Forage } & \multirow{2}{*}{ SEM } & \multirow{2}{*}{ p-value } \\
\hline & Alfalfa & Chinese leymus & & \\
\hline Dry matter $(\mathrm{g} / \mathrm{kg})$ & $358.2 \pm 5.65$ & $450.1 \pm 0.71$ & 5.70 & $<0.001$ \\
\hline Buffering capacity (mEq/kg DM) & $947.4 \pm 73.2$ & $296.0 \pm 6.70$ & 73.5 & $<0.001$ \\
\hline \multicolumn{5}{|l|}{ Chemical composition (g/kg DM) } \\
\hline Neutral detergent fiber & $374.2 \pm 4.39$ & $630.8 \pm 8.02$ & 9.14 & 0.001 \\
\hline Acid detergent fiber & $269.9 \pm 1.52$ & $324.3 \pm 3.94$ & 3.53 & $<0.001$ \\
\hline Hemicellulose & $105.6 \pm 5.76$ & $296.6 \pm 1.97$ & 6.09 & 0.001 \\
\hline Crude protein & $229.0 \pm 0.73$ & $67.1 \pm 0.34$ & 0.81 & $<0.001$ \\
\hline Water-soluble carbohydrates & $37.30 \pm 1.07$ & $81.3 \pm 0.02$ & 1.07 & $<0.001$ \\
\hline \multicolumn{5}{|l|}{ Vitamins content (mg/kg DM) } \\
\hline Thiamin & $8.858 \pm 0.28$ & $5.317 \pm 0.19$ & 0.33 & $<0.001$ \\
\hline Riboflavin & $90.35 \pm 1.10$ & $28.90 \pm 0.93$ & 1.44 & $<0.001$ \\
\hline Niacin & $1.950 \pm 0.11$ & $0.967 \pm 0.06$ & 0.12 & 0.001 \\
\hline Pantothenic acid & $31.82 \pm 0.39$ & $10.18 \pm 0.33$ & 0.51 & $<0.001$ \\
\hline Pyridoxine & $2.688 \pm 0.10$ & $2.082 \pm 0.09$ & 0.13 & $<0.01$ \\
\hline a-Tocopherol & $205.9 \pm 5.79$ & $107.0 \pm 3.34$ & 7.88 & $<0.01$ \\
\hline
\end{tabular}

DM, dry matter; SEM, Standard error of means. 
Table 2. Fermentation characteristics of alfalfa and Chinese leymus silages

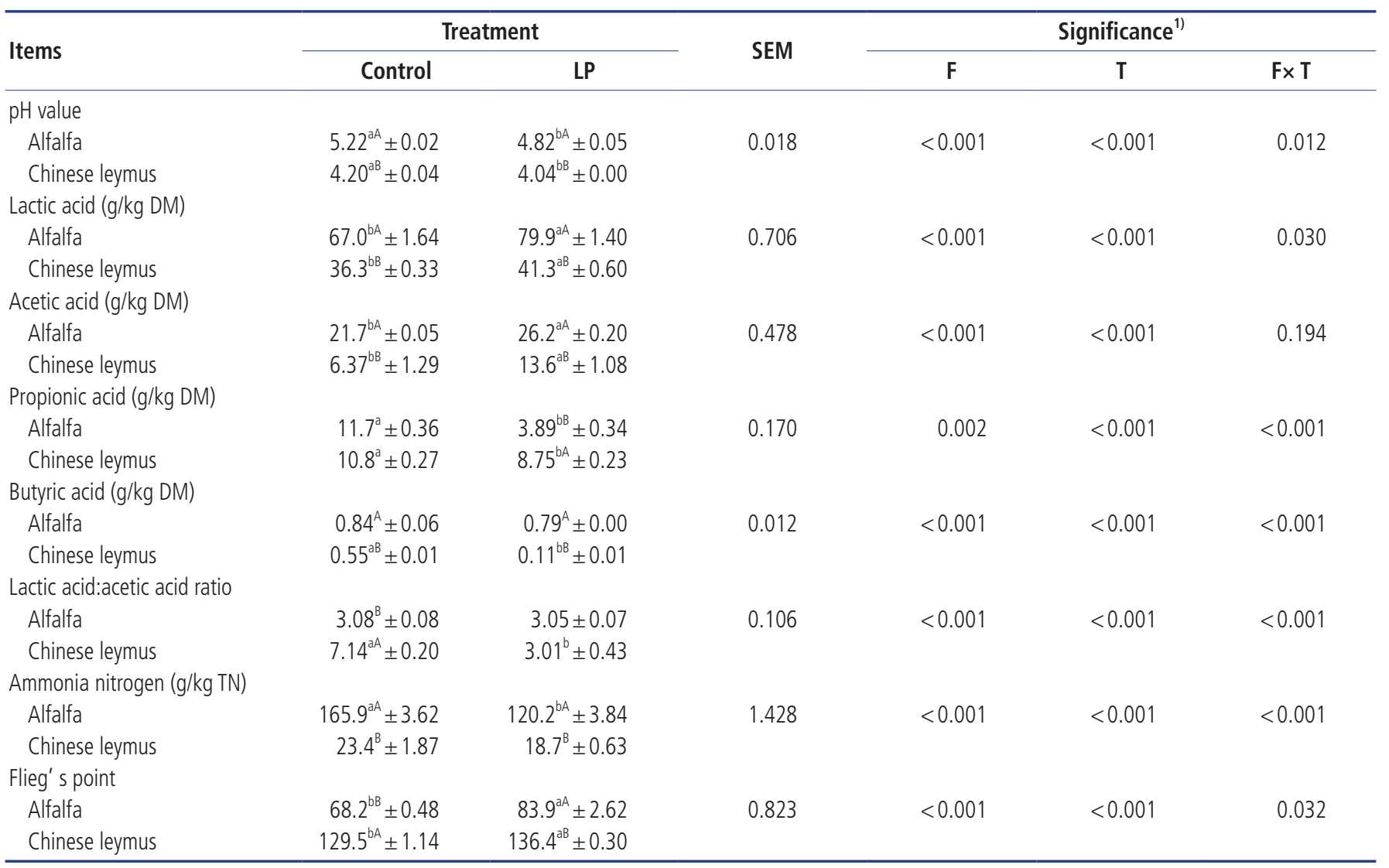

LP, Lactobacillus plantarum inoculant; SEM, standard error of means; DM, dry matter; TN, total nitrogen.

1) $F$, forage type; $T$, treatment; $F \times T$, interaction between forage type and treatment.

Means within the same row $\left.{ }^{(a, b}\right)$ or within the same column $\left(^{A, B}\right)$ with difference superscripts differ significantly from each other $(p<0.05)$.

alfalfa and Chinese leymus silages. For the Chinese leymus silage, the butyric acid levels and ratio of lactic acid levels to acetic acid levels in the LP-treated silage were significantly $(\mathrm{p}<0.05)$ lower those in the control. For the alfalfa silage, the ammonia nitrogen content was significantly $(p<0.01)$ lowered by the LP inoculant. The $\mathrm{pH}$ value of the Chinese leymus silage was significantly $(\mathrm{p}<0.05)$ lower than that of the alfalfa silage, and the lactic acid, acetic acid and ammonia nitrogen levels in the Chinese leymus silage were significantly $(\mathrm{p}<0.05)$ lower than those in the alfalfa silage. The LP inoculants significantly $(p<0.05)$ increased the Flieg's points of the alfalfa and Chinese silages, and the Flieg's point of the Chinese leymus silage was significantly $(\mathrm{p}<0.001)$ higher than that of the alfalfa silage.

\section{Chemical compositions of alfalfa and Chinese leymus silages}

The chemical compositions of the alfalfa and Chinese leymus silages are shown in Table 3. There was no significant difference ( $p>0.05$ ) in DM, WSC, NDF, and HC levels between the control and LP treatments of the alfalfa and Chinese leymus silages. For the alfalfa silage, the CP content of the LP treat- ment was significantly $(\mathrm{p}<0.05)$ higher than that of the control. For the Chinese leymus silage, the ADF content of the LP treatment was significantly $(\mathrm{p}<0.01)$ lower than that of the control.

\section{Vitamin concentrations of alfalfa and Chinese leymus silages}

The vitamin concentrations in the alfalfa and Chinese leymus silages are listed in Table 4 . After 45 days of ensiling, the thiamin, riboflavin, niacin, pantothenic acid and pyridoxine concentrations in the alfalfa and Chinese leymus silages were significantly $(\mathrm{p}<0.05)$ lower than those in the corresponding raw materials. Upon ensilage without the LP inoculant, the thiamin, riboflavin, niacin, pantothenic acid, pyridoxine and a-tocopherol levels in alfalfa decreased by $72.1 \%, 42.2 \%, 61.9 \%$, $42.2 \%, 57.6 \%$, and $30.7 \%$, respectively, after 45 days of fermentation; upon inoculation with LP, the thiamin, riboflavin, niacin, pantothenic acid, pyridoxine, and $\alpha$-tocopherol levels decreased by $81.2 \%, 52.9 \%, 71.4 \%, 53.2 \%, 58.8 \%$, and $8.0 \%$, respectively. Upon ensilage without the LP inoculant, the thiamin, riboflavin, niacin, pantothenic acid, and pyridoxine levels in Chinese leymus decreased by $54.1 \%, 60.2 \%, 64.8 \%, 60.3 \%$, 
Table 3. Chemical compositions of alfalfa and Chinese leymus silages

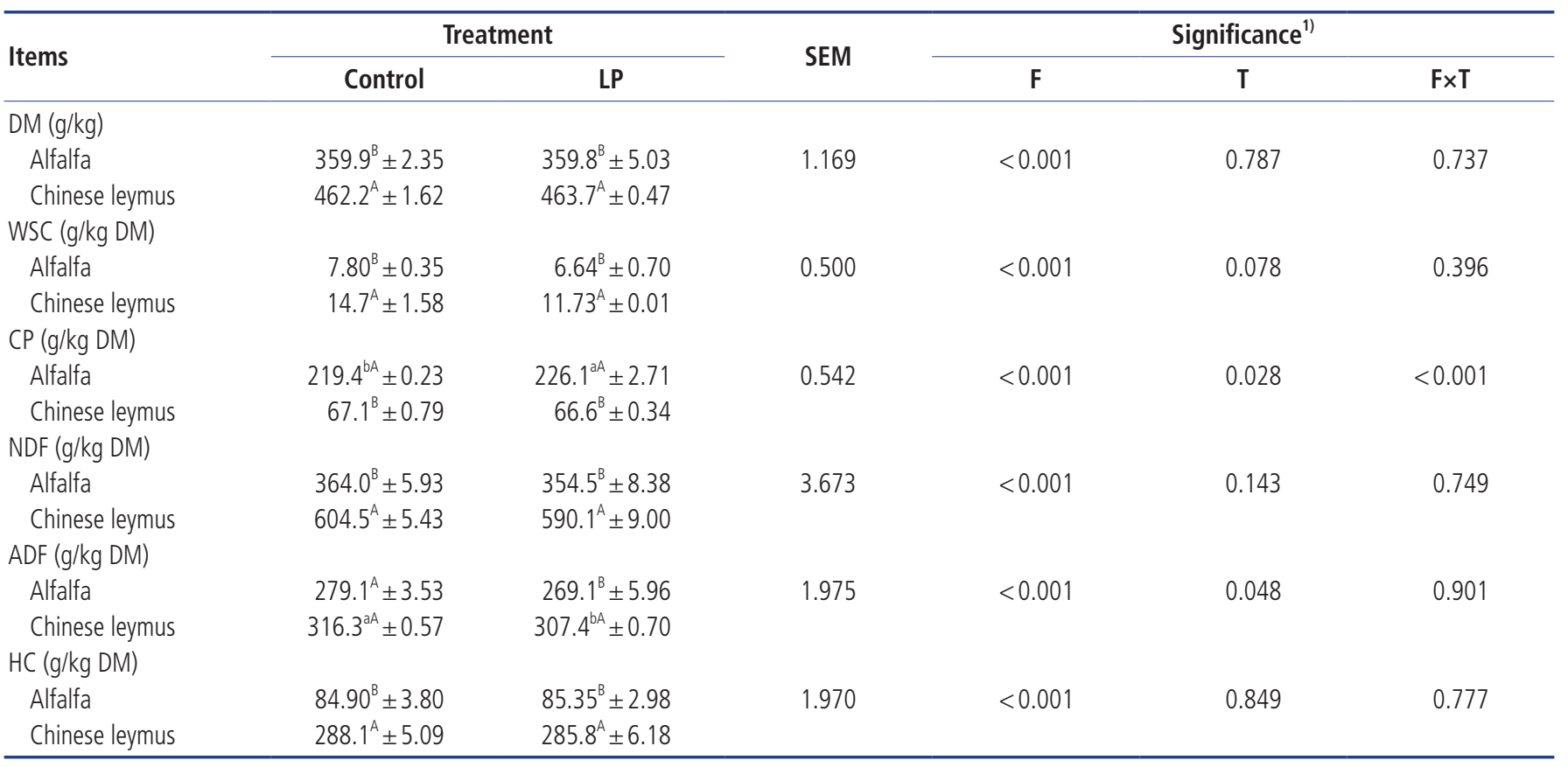

LP, Lactobacillus plantarum inoculant; SEM, standard error of means; DM, dry matter; WSC, water-soluble carbohydrate; CP, crude protein; NDF, neutral detergent fiber; ADF, acid detergent fiber; $\mathrm{HC}$, hemicellulose.

1) $F$, forage type; $T$, treatment; $F \times T$, interaction between forage type and treatment.

Means within the same row ${ }^{(a, b)}$ or within the same column $\left(^{A, B}\right)$ with difference superscripts differ significantly from each other $(p<0.05)$.

and $66.4 \%$, respectively, after 45 days of fermentation, while inoculation with LP decreased the thiamin, riboflavin, niacin, pantothenic acid, and pyridoxine levels by $59.4 \%, 65.1 \%$,
$90.4 \%, 66.4 \%, 65.2 \%$, respectively. However, the a-tocopherol content of untreated and LP-treated Chinese leymus silage increased by $52.1 \%$ and $49.9 \%$, respectively. After 45 days of

Table 4. Vitamin concentrations of alfalfa and Chinese leymus silages

\begin{tabular}{|c|c|c|c|c|c|c|}
\hline \multirow{2}{*}{ Items } & \multicolumn{2}{|c|}{ Treatment } & \multirow{2}{*}{ SEM } & \multicolumn{3}{|c|}{ Significance $^{1)}$} \\
\hline & Control & LP & & $\mathrm{F}$ & $T$ & $\mathrm{~F} \times \mathrm{T}$ \\
\hline \multicolumn{7}{|l|}{ Thiamin (mg/kg DM) } \\
\hline Chinese leymus & $2.438^{a} \pm 0.08$ & $2.158^{\mathrm{bA}} \pm 0.06$ & & & & \\
\hline \multicolumn{7}{|c|}{ Riboflavin (mg/kg DM) } \\
\hline Alfalfa & $52.21^{\mathrm{aA}} \pm 0.55$ & $42.53^{\mathrm{bA}} \pm 0.15$ & 0.162 & $<0.001$ & $<0.001$ & $<0.001$ \\
\hline \multicolumn{7}{|l|}{ Niacin (mg/kg DM) } \\
\hline Alfalfa & $0.743^{\mathrm{aA}} \pm 0.03$ & $0.558^{\mathrm{bA}} \pm 0.03$ & 0.017 & $<0.001$ & 0.001 & 0.396 \\
\hline Chinese leymus & $0.340^{\mathrm{aB}} \pm 0.05$ & $0.093^{\mathrm{bB}} \pm 0.02$ & & & & \\
\hline \multicolumn{7}{|c|}{ Pantothenic acid (mg/kg DM) } \\
\hline Alfalfa & $18.38^{\mathrm{aA}} \pm 0.40$ & $14.89^{\mathrm{bA}} \pm 0.07$ & 0.109 & $<0.001$ & $<0.001$ & $<0.001$ \\
\hline Chinese leymus & $4.043^{\mathrm{aB}} \pm 0.15$ & $3.425^{\mathrm{bB}} \pm 0.04$ & & & & \\
\hline \multicolumn{7}{|c|}{ a-Tocopherol (mg/kg DM) } \\
\hline Alfalfa & $142.6^{b} \pm 6.96$ & $189.4^{\mathrm{a}} \pm 8.94$ & 3.926 & 0.591 & 0.030 & 0.020 \\
\hline Chinese leymus & $162.8 \pm 7.38$ & $160.4 \pm 2.02$ & & & & \\
\hline
\end{tabular}

LP, Lactobacillus plantarum inoculant; SEM, standard error of means; DM, dry matter.

1) $F$, forage type; $T$, treatment; $F \times T$, interaction between forage type and treatment.

Means within the same row ${ }^{(--C)}$ or within the same column $\left(^{A-B}\right)$ with difference superscripts differ significantly from each other $(p<0.05)$. 
ensiling, the thiamin, riboflavin, niacin and pantothenic acid content of LP-treated silage was significantly $(\mathrm{p}<0.05)$ lower than that of untreated silage for both alfalfa and Chinese leymus silages. The $\alpha$-tocopherol content of LP-treated silage was significantly $(\mathrm{p}<0.05)$ higher than that of untreated silage for the alfalfa silage. There was no significant $(p>0.05)$ difference in pyridoxine content between the control and LP treatments for the alfalfa and Chinese leymus silages.

\section{DISCUSSION}

By the end of ensiling, the addition of LP inoculant had a positive effect on alfalfa and Chinese leymus silage fermentation, as demonstrated by the low $\mathrm{pH}$ and butyric acid and ammonia nitrogen content and high lactic acid concentration in the inoculated silage. After 45 days of ensiling, the loss of WSC content in both forages was approximately $80 \%$, which was due to the conversion of WSC to organic acid, while there was no significant difference in residual WSC content between the control and LP-treated silages. The $\mathrm{pH}$ of the alfalfa silage was much higher than that of the Chinese leymus silage, probably due to the high buffering capacity and low WSC content of alfalfa. The butyric acid and ammonia nitrogen concentrations in the alfalfa silage were significantly higher than those in the Chinese leymus silage in the present study, which indicates that alfalfa undergoes a greater degree of proteolysis than Chinese leymus. This result is consistent with previous observations of Papadopoulos and Mckersie [19] and can perhaps be explained by the high susceptibility of alfalfa proteins to proteolysis [20]. The higher acetic acid content and lower ratio of lactic acid to acetic acid in the control alfalfa silage than in the control Chinese leymus silage were indicative of the activity of heterofermentative lactic acid bacteria. Based on the Flieg's points of the alfalfa and Chinese leymus silages, the fermentation quality of the Chinese leymus silage was better than that of the alfalfa silage, and the use of LP inoculant could improve the fermentation quality of both silages.

Many studies have investigated the $\alpha$-tocopherol and $\beta$ carotene present in silage [6-9], while the B vitamins in alfalfa and Chinese leymus silages have not yet been discussed in the literature [7]. The thiamine concentrations in the alfalfa and Chinese leymus silages were 2.475 and $1.663 \mathrm{mg} / \mathrm{kg} \mathrm{DM}$, respectively, which were close to the level $(1.37 \mathrm{mg} / \mathrm{kg} \mathrm{DM})$ reported by Beaudet et al [21]. The riboflavin levels in the alfalfa and Chinese leymus silages were 52.21 and $42.53 \mathrm{mg} / \mathrm{kg}$ $\mathrm{DM}$, respectively, which were higher than the value reported by Schwab et al [22] in corn silage ( $3.5 \mathrm{mg} / \mathrm{kg} \mathrm{DM}$ ) but similar to the value reported by Beaudet et al [21] in corn silage (73.2 $\mathrm{mg} / \mathrm{kg} \mathrm{DM})$. The niacin levels in the alfalfa and Chinese leymus silages were 0.743 and $0.558 \mathrm{mg} / \mathrm{kg} \mathrm{DM}$, respectively, which were lower than value ( 1.1 to $34 \mathrm{mg} / \mathrm{kg}$ ) previously reported by Ballet al [7] in silage. The pantothenic acid levels in the alfalfa and Chinese leymus silages were 18.38 and 14.89 $\mathrm{mg} / \mathrm{kg} \mathrm{DM}$, respectively, which were higher than the value reported by Schwab et al [22] in corn silage ( $1.5 \mathrm{mg} / \mathrm{kg} \mathrm{DM})$. The pyridoxine levels in the alfalfa and Chinese leymus silages were 1.140 and $1.108 \mathrm{mg} / \mathrm{kg} \mathrm{DM}$, respectively, which were lower than the value reported by Schwab et al [22] in corn silage (1.9 mg/kg DM). Based on the results of the present study, the thiamin, riboflavin, niacin, pantothenic acid, pyridoxine and $\alpha$-tocopherol levels in the alfalfa forage were significantly higher than those in the Chinese leymus. The observed variability in B vitamin levels in silage suggests that many factors contribute to the variability, including forage species, climatic conditions, maturity and storage methods [7]. After 45 days of ensiling, the thiamin, riboflavin, niacin, pantothenic acid and pyridoxine concentrations in the untreated alfalfa silage decreased by $72.1 \%, 42.2 \%, 61.9 \%, 42.2 \%$, and $57.6 \%$, respectively. For the untreated Chinese leymus silage, the levels of thiamin, riboflavin, niacin, pantothenic acid and pyridoxine decreased by $54.1 \%, 60.2 \%, 64.8 \%, 60.3 \%$, and $66.4 \%$, respectively. Except for pyridoxine in Chinese leymus, the loss of $B$ vitamins increased upon inoculation with LP. The decrease in thiamine content in the present study was similar to the results of Rao and Basu [23], who found that thiamine levels decreased during fermentation with lactobacilli. However, the reason underlying the observed influence of the lactic acid bacterial inoculant on B vitamin content in the present study. The continued increase in dairy productivity and quality of ruminants has resulted in increased B vitamin requirements [7]. Many studies conducted on other fermentation products, such as yogurt, cheeses, tarhana, and cereals $[10,24-26]$, have shown that the levels of B-group vitamins in these fermented products increased after fermentation due to the synthesis of $B$ vitamins by selected lactic acid bacteria [26]. Therefore, it may be possible to select B-vitamin-producing lactic acid bacteria to increase the $B$ vitamin concentrations in silage.

$\alpha$-Tocopherol is an important antioxidant. The $\alpha$-tocopherol content of the Chinese leymus forage was similar to the value reported by Ballet et al [7] in grasses harvested during the early to late flowering stages but higher than the value reported by Liu et al [9] for napier grass. After 45 days of fermentation, the $a$-tocopherol content of the untreated Chinese leymus silage increased by $52.1 \%$ compared with that of raw Chinese leymus. To date, there has been no clear explanation for the changes in $\alpha$-tocopherol levels observed during ensiling. Lindqvist et al [27] hypothesized that $\alpha$-tocopherol-producing microorganisms exist on plants [28]. However, after 45 days of fermentation, the a-tocopherol content of the untreated alfalfa silage decreased by $30.7 \%$ compared with that of raw alfalfa, while the $a$-tocopherol content of the LP-treated alfalfa silage decreased by $8.0 \%$; perhaps the $\alpha$-tocopherol content 
is associated with the $\mathrm{pH}$ of silage. Liu et al [9] found that the residual rate of $\alpha$-tocopherol was high at $\mathrm{pH} 4.0$, and higher or lower $\mathrm{pH}$ values decreased the residual rate of $\alpha$ tocopherol. Therefore, the high $\mathrm{pH}$ of LP-treated and untreated alfalfa silage (4.82 and 5.22, respectively) resulted in loss of a-tocopherol in alfalfa silage. The LP-treated silage retained a higher amount of $\alpha$-tocopherol than the control silage due to the low $\mathrm{pH}$ of the LP-treated silage.

In conclusion, prior to ensiling, the levels of five B-group vitamins (thiamin, riboflavin, niacin, pantothenic acid, and pyridoxine) and $\alpha$-tocopherol in alfalfa were significantly higher than those in Chinese leymus. With or without LP inoculation, the levels of the five B-group vitamins in alfalfa and Chinese leymus decreased after 45 days of ensiling, while the a-tocopherol content of Chinese leymus increased. The LP inoculant improved the fermentation quality of both the alfalfa and Chinese leymus silages but increased the thiamin, riboflavin, niacin and pantothenic acid loss in the two forages after 45 days of fermentation. In addition, after fermentation, the a-tocopherol content of alfalfa decreased, but the LP-treated silage retained more $\alpha$-tocopherol than the untreated silage.

\section{CONFLICT OF INTEREST}

We certify that there is no conflict of interest with any financial organization regarding the material discussed in the manuscript.

\section{ACKNOWLEDGMENTS}

This work was financially supported by the China Forage and Grass Research System (CARS-34), the Key Research and Development Program in Ningxia Hui Autonomous Region (2017BY082), the Agricultural Technology Test demonstration and Service Support Program in China (131821301064071005).

\section{REFERENCES}

1. Jensen SK, Johannsen AKB, Hermansen JE. Quantitative secretion and maximal secretion capacity of retinol, $\beta$-carotene and $\alpha$-tocopherol into cows' milk. J Dairy Res 1999;66: 511-22. https://doi.org/10.1017/S0022029999003805

2. Keuth S, Bisping B. Formation of vitamins by pure cultures of tempe moulds and bacteria during the tempe solid substrate fermentation. J Appl Bacteriol 1993;75:427-34. https://doi. org/10.1111/j.1365-2672.1993.tb02798.x

3. Elgersma A, Søegaard K, Jensen SK. Vitamin contents in forage herbs. Aspects Appl Biol 2012;115:75-80.

4. McDowell LR. Vitamins in animal nutrition: comparative aspects to human nutrition. San Diego, CA, USA: Academic Press; 1989.

5. Booth VH. The a-tocopherol content of forage crops. J Sci
Food Agric 1964;15:342-4. https://doi.org/10.1002/jsfa.2740 150512

6. Hidiroglou M, Batra TR, Roy GL. Changes in plasma $\alpha$-tocopherol and selenium of gestating cows fed hay or silage. J Dairy Sci 1994;77:190-5. https://doi.org/10.3168/jds.S00220302(94)76941-1

7. Ballet N, Robert JC, Williams PEV. Vitamins in forages. In: Givens DI, Owen E, Axford RFE, Omed HM, editors. Forage evaluation in ruminant nutrition. Oxon, UK: CABI Publishing; 2000. p. 399-431 (Chapter 19)

8. Shingfield KJ, Salo-Väänänen P, Pahkala E, et al. Effect of forage conservation method, concentrate level and propylene glycol on the fatty acid composition and vitamin content of cows' milk. J Dairy Res 2005;72:349-61. https://doi.org/10.1017/ S0022029905000919

9. Liu QH, Shao T, Bai YF. The effect of fibrolytic enzyme, Lactobacillus plantarum and two food antioxidants on the fermentation quality, alpha-tocopherol and beta-carotene of high moisture napier grass silage ensiled at different temperatures. Anim Feed Sci Technol 2016;221:1-11. https://doi.org/10. 1016/j.anifeedsci.2016.08.020

10. Certel M, Erbas M, Uslu MK, Erbas MO. Effects of fermentation time and storage on the water-soluble vitamin contents of tarhana. J Sci Food Agric 2007;87:1215-8. https://doi.org/ $10.1002 /$ jsfa. 2810

11. Ochanda SO, Akoth OC, Mwasaru MA, Kagwiria OJ, Mutiso MF. Effects of malting and fermentation treatments on group B-vitamins of red sorghum, white sorghum and pearl millets in Kenya. J Appl Biosci 2010;34:2128-34.

12. Broderick GA, Kang JH. Automated simultaneous determination of ammonia and total amino acids in ruminal fluid and in vitro media. J Dairy Sci 1980;63:64-75. https://doi. org/10.3168/jds.S0022-0302(80)82888-8

13. Playne MJ, McDonald P. The buffering constituents of herbage and of silage. J Sci Food Agric 1966;17:264-8. https://doi.org/ 10.1002/jsfa.2740170609

14. Murphy RP. A method for the extraction of plant samples and the determination of total soluble carbohydrates. J Sci Food Agric 1958;9:714-7. https://doi.org/10.1002/jsfa.27400 91104

15. Association of Official Analytical Chemists (AOAC). Protein (crude) in animal feed and pet food 984.13. In: Cunniff PA, editor. Official Methods of Analysis of Official Analytical Chemists International, 16th edn volume I chapter 4. Arlington, VA, USA: AOAC International; 1995.

16. Van Soest PJ, Robertson JB, Lewis BA. Methods for dietary fiber, neutral detergent fiber, and nonstarch polysaccharides in relation to animal nutrition. J Dairy Sci 1991;74:3583-97. https://doi.org/10.3168/jds.S0022-0302(91)78551-2

17. Kilic A. Silo feed (instruction, education and application proposals). Izmir, Turkey: Bilgehan Press; 1986.

18.IBM SPSS Statistics for Windows, version 19.0; Armonk, NY, 
USA; IBM Corp: 2010.

19. Papadopoulos YA, Mckersie BD. A comparison of protein degradation during wilting and ensiling of six forage species. Can J Plant Sci 1983;63:903-12. https://doi.org/10.4141/cjps83114

20. Mckersie BD, Buchanan-Smith J. Changes in the levels of proteolytic enzymes in ensiled alfalfa forage. Can J Plant Sci 1982; 62:111-6. https://doi.org/10.4141/cjps82-017

21. Beaudet V, Gervais R, Graulet B, et al. Effects of dietary nitrogen levels and carbohydrate sources on apparent ruminal synthesis of some B vitamins in dairy cows. J Dairy Sci 2016;99:2730-9. https://doi.org/10.3168/jds.2015-10521

22.Schwab EC, Schwab CG, Shaver RD, et al. Dietary forage and nonfiber carbohydrate contents influence B-vitamin intake, duodenal flow, and apparent ruminal synthesis in lactating dairy cows. J Dairy Sci 2006;89:174-87. https://doi.org/10. 3168/jds.S0022-0302(06)72082-3

23. Rao RV, Basu KP. Effect of dahi fermentation on the thiamine, riboflavin and nicotinic acid contents of milk. Indian J Dairy
Sci 1952;5:1-8.

24. Alm L. Effect of fermentation on B-vitamin content of milk in Sweden. J Dairy Sci 1982;65:353-9. https://doi.org/10.3168/ jds.S0022-0302(82)82199-1

25. Shahani KM, Chandan RC. Nutritional and healthful aspects of cultured and culture-containing dairy foods. J Dairy Sci 1979;62:1685-94.

26. Capozzi V, Russo P, Dueñas MT, López P, Spano G. Lactic acid bacteria producing B-group vitamins: a great potential for functional cereals products. Appl Microbiol Biotechnol 2012; 96:1383-94. https://doi.org/10.1007/s00253-012-4440-2

27.Lindqvist H, Nadeau E, Jensen SK. Alpha-tocopherol and $\beta$ -carotene in legume-grass mixtures as influenced by wilting, ensiling and type of silage additive. Grass Forage Sci 2012;67: 119-28. https://doi.org/10.1111/j.1365-2494.2011.00827.x

28. Tani Y, Tsumura H. Screening for tocopherol-producing microorganisms and a-tocopherol production by Euglena gracilis Z. Agric Biol Chem 1989;53:305-12. https://doi.org/10.1080/ 00021369.1989 .10869324 